\title{
PERANCANGAN SISTEM APLIKASI PEMINJAMAN DAN PENGEMBALIAN MOBIL DI RIFAZA RENTAL MOBIL
}

\author{
Ahmad Linaldi ${ }^{1}$, Lukman ${ }^{2}$, Nasrulloh Isnain ${ }^{3}$ \\ 1,2,3 Teknik Informatika, FTIK, Universitas Indraprasta PGRI \\ Jl.Raya Tengah No. 80, RT.1/RW.3,Gedong, Kec. PS. Rebo, Kota Jakarta Timur \\ 1Ahmadlinaldi43@gmail.com, ${ }^{2}$ Lkmnaja50@gmail.com, ${ }^{3}$ nasrullohunindra@yahoo.co.id
}

\begin{abstract}
ABSTRAK
Kemajuan Teknologi sekarang sudah sangat pesat sekali. Hal ini terbukti dengan ditemukannya komputer berkecepatan tinggi dalam era komputerisasi saat ini. Pemakaian sistem komputer sudah memasyarakat di bidang pendidikan, penelitian, perkantoran maupun masyarakat umum. Selain itu komputer juga berfungsi untuk membantu memudahkan pekerjaan pengolahan data, pengolahan angka, pengolahan gambar atau grafika melalui suatu perangkat lunak baik secara paket program atau dengan bahasa pemrograman tertentu. Rifaza Rental Mobil saat ini untuk peminjaman dan pengembalian mobilnya masih menggunakan media kertas atau tulis tangan yang dapat menyebabkan kekeliruan dalam pencatatan data peminjaman dan pengembalian mobilnya, dengan penggunaan teknologi mempermudah pencatatan peminjaman dan pengembalian yaitu dengan aplikasi java berbasis desktop.Oleh karena itu, penulis mencoba untuk membuat aplikasi java berbasis desktop diharapkan dapat mempermudah dalam pencatatan data peminjaman dan pengembalian mobilnya. Dari hasil uji aplikasi, dapat diketahui bahwa aplikasi Sistem Informasi Rental Mobil dapat memberikan kemudahan pada pelanggan dalam proses peminjaman dan pengembalian mobil dan untuk admin dapat memberikan kemudahan dalam mengelola proses pencatatan peminjaman dan pengembalianmobil, laporan dan pengeluaran biaya.
\end{abstract}

Kata Kunci : Perancangan Aplikasi, Peminjaman, Pengembalian, Java, Desktop

\begin{abstract}
Advances in technology are now very fast. This is evidenced by the discovery of computers that are increasingly high in the current era of computerization. The use of computer systems has become popular in the fields of education, research, offices and the general public. In addition, the computer also serves to help facilitate the work of data processing, number processing, image processing or graphics through a software program either in a program package or with a particular programming language. Rifaza Car Rental currently uses paper or handwritten media for borrowing and borrowing cars which can lead to recording of loan data and car management, with the use of borrowing and activity recording technology, namely desktop-based java applications. Therefore, to create java-based applications The desktop is expected to make it easier to record loan data and car adjustments. From the results of the application test, it can be seen that the Rental Information System application can provide convenience to customers in the loan process and for admins it can provide convenience in managing car loans and adjustments, reports and expenses.
\end{abstract}

Key Word: Application Design, Borrowing, Returns, Java, Desktop

\section{PENDAHULUAN}

Kemajuan Teknologi sekarang sudah sangat pesat sekali. Hal ini terbukti dengan ditemukannya komputer berkecepatan tinggi dalam era komputerisasi saat ini. Pemakaian sistem komputer sudah memasyarakat di bidang pendidikan, penelitian, perkantoran maupun masyarakat umum. Selain itu komputer juga berfungsi untuk membantu memudahkan pekerjaan pengolahan data, pengolahan angka, pengolahan gambar atau grafika melalui suatu perangkat lunak baik secara paket program atau dengan bahasa pemrograman tertentu (Anomi, 2010).

Rifaza Rental Mobil saat ini untuk peminjaman dan pengembalian mobilnya masih menggunakan media kertas atau tulis tangan yang dapat menyebabkan kekeliruan dalam pencatatan data peminjaman dan pengembalian mobilnya, dengan penggunaan teknologi mempermudah pencatatan peminjaman dan pengembalian yaitu dengan aplikasi java berbasis desktop. Oleh karena itu, penulis 
mencoba untuk membuat aplikasi java berbasis desktop diharapkan dapat mempermudah dalam pencatatan data peminjaman dan pengembalian mobilnya.

Tujuan dari penelitian ini adalah untuk membuat Perancangan Sistem Aplikasi Peminjaman dan Pengembalian Mobil di Rifaza Rental Mobil. Untuk memudahkan penginputan data peminjaman dan pengembalian. Memudahkan dalam proses pencarian data agar lebih cepat dan efisien.

"Perancangan adalah suatu kegiatan yang memiliki tujuan untuk mendesign sistem baru yang dapat menyelesaikan masalah-masalah yang dihadapi perusahaan yang diperoleh dari pemilihan alternatif sistem yang terbaik". (Ladjamudin, 2011) "Perancangan adalah sebuah proses untuk mendefinisikan sesuatu yang akan dikerjakan dengan menggunakan teknik yang bervariasi serta didalamnya melibatkan deskripsi mengenai arsitektur serta detail komponen dan juga keterbatasan yang akan dialami dalam proses pengerjaannya." (Rizky, 2011) "Perancangan adalah proses pengembangan spesifikasi sistem baru berdasarkan hasil rekomendasi analisis sistem". (Kusrini, 2012)

"Suatu sistem adalah sekelompok unsur yang erat hubungannya satu dengan yang lain, yang berfungsi bersama-sama untuk mencapai tujuan tertentu". (Sutabri, 2016) "Sistem merupakan sekelompok unsur yang erat berhubungan satu dengan yang lainnya, yang berfungsi bersamasama untuk mencapai tujuan tertentu". (Mulyadi, 2012) "Sistem merupakan sekelompok komponen yang saling berhubungan, bekerja sama untuk mencapai tujuan bersama dengan menerima input serta menghasilkan output dalam transformasi yang teratur". (Kurniawan \& Herryanto, 2017)

"Perancangan sistem adalah sebuah kegiatan merancang dan menentukan cara mengolah sistem informasi dari hasil analisa sistem sehingga dapat memenuhi kebutuhan dari pengguna termasuk diantaranya perancangan user interface data dan aktivitas proses". (O’Brien, 2013) "perancangan sistem adalah penentuan proses dan data yang diperlukan oleh sistem baru, jika sistem itu berbasis komputer, perancangan dapat dinyatakan spesifikasi peralatan yang digunakan". (Raymond Mcleod, 2012)

"Aplikasi adalah perangkat lunak yang digunakan untuk tujuan tertentu, seperti mengolah dokumen, mengatur Windows dan permainan (game) dan sebagainya".(Hakim, 2012) Sequence diagram menggambarkan kelakuan objek pada use case dengan mendeskripsikan waktu hidup objek dan pesan yang dikirimkan dan diterima antar objek (Wira et al., 2019).

\section{METODE PENELITIAN}

Penelitian dilaksanakan pada Maret 2021 sampai Agustus 2021.Tempat penelitian dalam proses pengumpulan data yang menunjang proses penyusunan penelititan ini dilakukan di Rifaza Rental Mobil.

Metode penelitian yang digunakan oleh penulis adalah metode grounded (grounded research) yaitu suatu metode penelitian berdasarkan pada fakta dan menggunakan analisis perbandingan dengan tujuan mengadakan generalisasi empiris, menetapkan konsep, membuktikan teori, mengembangkan teori, pengumpulan dan analisis data dalam waktu yang bersamaan. Dalam riset ini data merupakan sumber teori atau teori berdasarkan data.

Jadi, dapatlah ditarik kesimpulan bahwa grounded research adalah metode penelitian kualitatif yang mencoba mengonstruksi atau merekonstruksi teori atas suatu fakta yang terjadi di lapangan berdasarkan data melalui analisis induktif.

\section{Metode Pengumpulan Data}

Metode pengumpulan data yang dilakukan oleh penulis untuk mendapatkan data-data serta informasi untuk mendukung penyempurnaan hasil dari penelitian ini antara lain :

\section{Studi Pustaka (Library Search)}


Pengumpulan data dan informasi dari kutipankutipan buku-buku referensi, situs-situs internet serta hasil laporan dan bahan lainnya yang berhubungan dengan Java, NetBeans, serta informasi yang berhubungan dengan masalah yang akan dibahas dalam tugas akhir ini. Dari bahan-bahan tersebut diambil teori-teori yang dapat dijadikan landasan untuk menganalisa masalah yang diketemukan dalam penelitian.

\section{Studi Lapangan (Field Research)}

Metode ini dilakukan penulis secara langsung untuk mengumpulkan data yang berhubungan dengan Perancangan Sistem Aplikasi Peminjaman dan Pengembalian Mobil Pada Rifaza Rental Mobil. Data-data tersebut penulis kumpulkan dengan cara sebagai berikut :

\section{Observasi}

Metode ini merupakan metode pengumpulan data yang cukup efektif. Metode observasi adalah pengamatan langsung terhadap suatu objek maupun kegiatan yang sedang berlangsung. Dalam penelitian ini penulis melakukan observasi di Rifaza Rental Mobil.

\section{Wawancara}

Pengumupulan data dengan wawancara ini dilakukan untuk mencari data dan informasi tentang hal-hal yang dibutuhkan dalam penelitian. Wawancara dilakukan dengan lembaga atau instansi yang dijadikan objek penelitian.

\section{HASIL DAN PEMBAHASAN}

Proses Bisnis dapat didefinisikan sebagai kumpulan dari proses dan berisi serangkaian aktifitas (task) yang saling berhubungan satu sama lain untuk menghasilkan suatu keluaran yang mendukung pada tujuan dan sasaran yang strategis dari perusahaan Sistem yang berjalan pada Rifaza Rental Mobil berupa yang meliputi:

1. Proses Peminjaman

Pelanggan melihat daftar sewa mobil, kemudian pelanggan memilih mobil yang ingin di sewa, admin memberikan formulir peminjaman ke pelanggan, pelanggan mengisi formulir peminjaman dan berapa lama sewa mobil nya, setelah pelanggan mengisi formulir peminjaman, pelanggan menyerahkan formulir peminjaman ke admin, admin kemudian membuatkan kwitansi pembayaran lalu admin menyerahkan ke pelanggan, pelanggan menerima kwitansi dan membayar sewa mobil, admin menyerahkan kunci dan STNK, kemudian admin membuat arsip data untuk dibuatkan laporan.

2. Proses Pengembalian

Pelanggan menyerahkan kunci dan STNK ke admin, admin menerima kunci dan STNK, admin menyerahkan formulir pengembalian ke pelanggan, pelanggan menerima formulir pengembalian dan mengisi formulir pengembalian, kemudian admin membuat arsip data untuk laporan.

3. Proses Laporan

Admin membuatkan laporan peminjaman dan pengembalian kemudian di serahkan ke pemilik.

\section{Usecase Diagram Sistem Berjalan}

Berikut adalah usecase diagram sistem berjalan pelanggan melakukan proses peminjaman dan pengembalian, serta admin memberikan laporan terhadap pemilik.

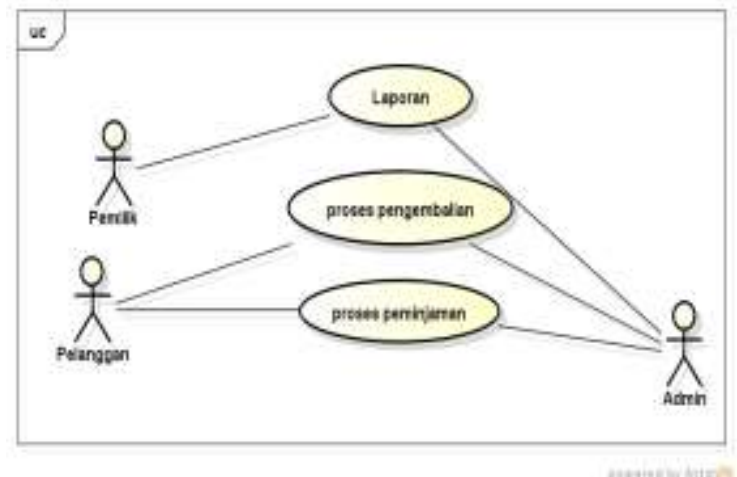

Gambar 1. Usecase Sistem Berjalan

\section{Activity Diagram Sistem Berjalan}

Activity Diagram Sistem Berjalan Peminjaman. Berikut gambar di bawah ini adalah activity diagram sistem berjalan proses peminjaman yang dimana pelanggan melakukan peminjaman mobil, kemudian admin memproses data peminjaman. 


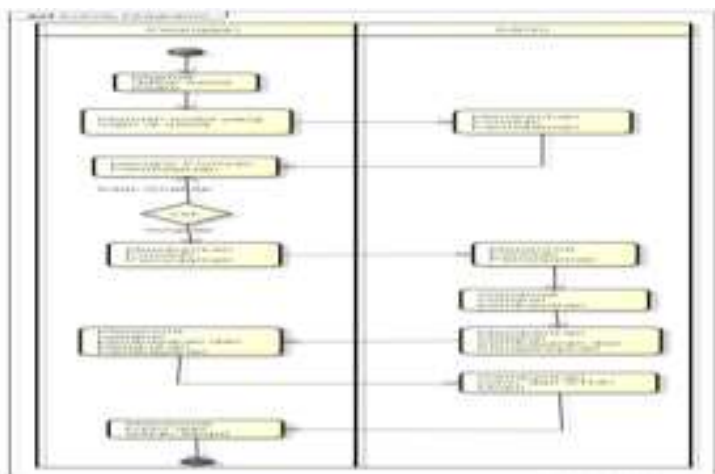

Gambar 2. Activity Diagram Sistem Berjalan Peminjaman.

Activity Diagram Sistem Berjalan Pengembalian.

Berikut gambar di bawah ini adalah activity diagram sistem berjalan proses pengembalian yang dimana pelanggan melakukan pengembalian mobil, kemudian admin memproses data pengembalian.

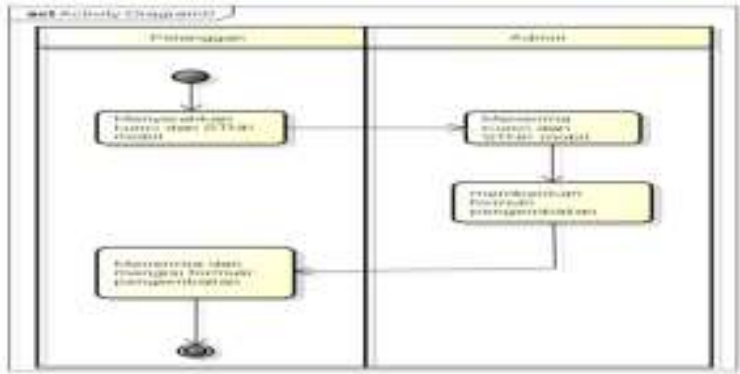

Gambar 3. Activity Diagram Sistem Berjalan Pengembalian.

Activity Diagram Sistem Berjalan Laporan.

Berikut gambar di bawah ini adalah activity diagram sistem berjalan proses laporan yang dimana admin membuat laporan peminjaman dan pengembalian mobil, kemudian admin menyerahkan laporan tersebut ke pemilik.

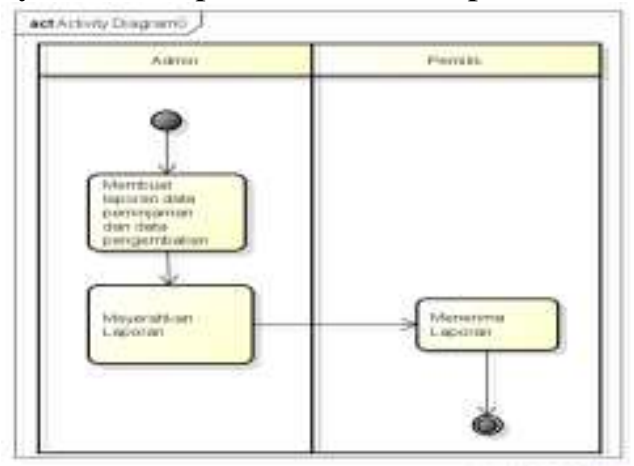

Gambar 4. Activity Diagram Sistem Berjalan Laporan.
Unified Modelling Language (UML) Sistem yang Diusulkan

\section{Use Case Diagram}

Berikut adalah use case diagram sistem usulan yang dimana admin dapat melakukan login, mengelola data user, data pelanggan, data mobil, data peminjaman, data pengembalian dan laporan.

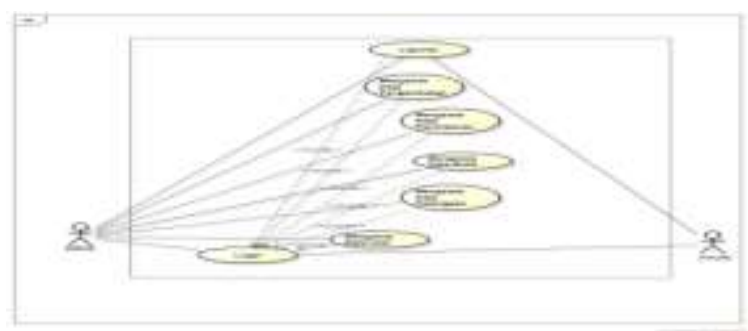

Gambar 5. Use Case Diagram Sistem Usulan

\section{Activity Diagram}

Activity Diagram Admin Login

Berikut adalah activity diagram admin login yang dimana admin melakukan proses login dengan memasukan kode user dan password.

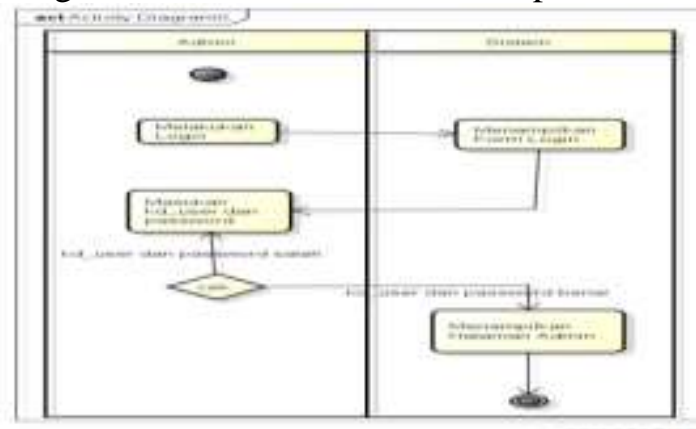

Gambar 6. Activity Diagram Admin Login Activity Diagram Admin Mengelola Data User Berikut adalah activity diagram admin mengelola data user yang dimana admin setelah proses login dengan memasukan kode user dan password admin dapat mengelola data user.

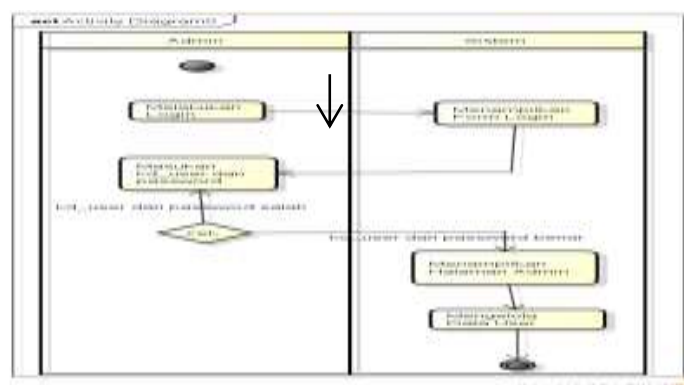

Gambar 7. Activity Diagram Admin Mengelola Data User

205 | Perancangan Sistem Aplikasi Peminjaman dan Pengembalian Mobil di Rifaza Rental Mobil 
Activity Diagram Admin Mengelola Data Pelanggan

Berikut adalah activity diagram admin mengelola data pelanggan yang dimana admin setelah proses login dengan memasukan kode user dan password admin dapat mengelola data pelanggan.

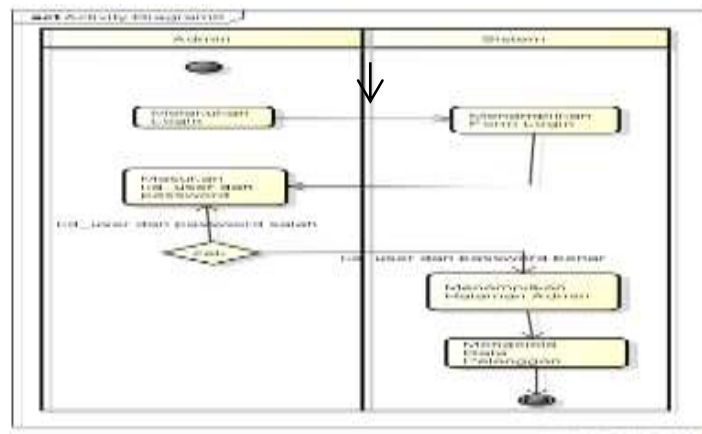

Gambar 8. Activity Diagram Admin Mengelola Data Pelanggan

Activity Diagram Admin Mengelola Data Mobil Berikut adalah activity diagram admin mengelola data mobil yang dimana admin setelah proses login dengan memasukan kode user dan password admin dapat mengelola data mobil.

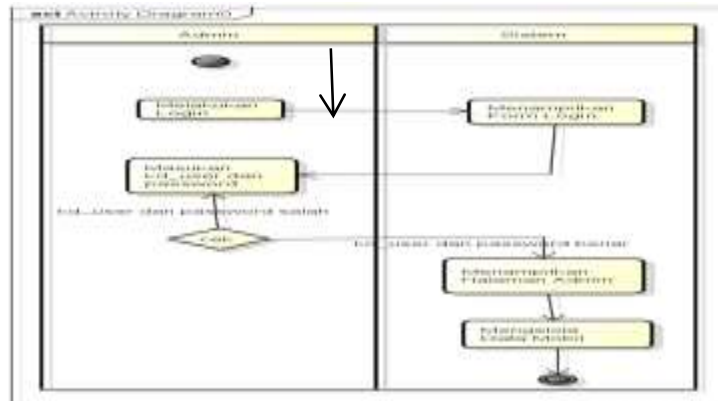

Gambar 9. Activity Diagram Admin Mengelola Data Mobil

Activity Diagram Admin Mengelola Data Peminjaman

Berikut adalah activity diagram admin mengelola data peminjaman yang dimana admin setelah proses login dengan memasukan kode user dan password admin dapat mengelola data peminjaman.

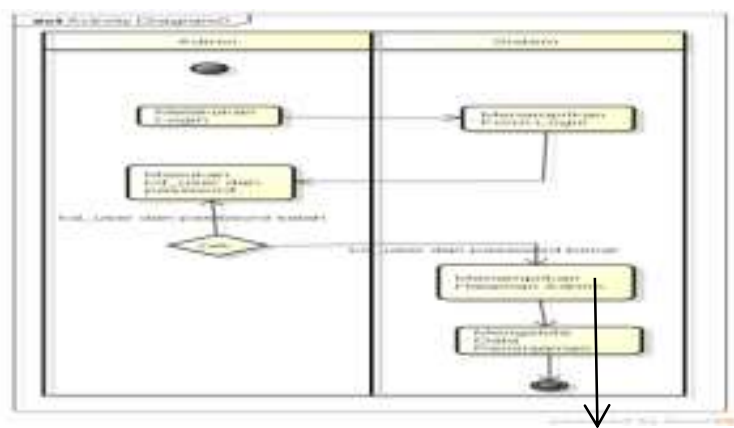

Gambar 10. Activity Diagram Admin Mengelola Data Peminjaman

Activity Diagram Admin Mengelola Data Pengembalian

Berikut adalah activity diagram admin mengelola data pengembalian yang dimana admin setelah proses login dengan memasukan kode user dan password admin dapat mengelola data pengembalian.

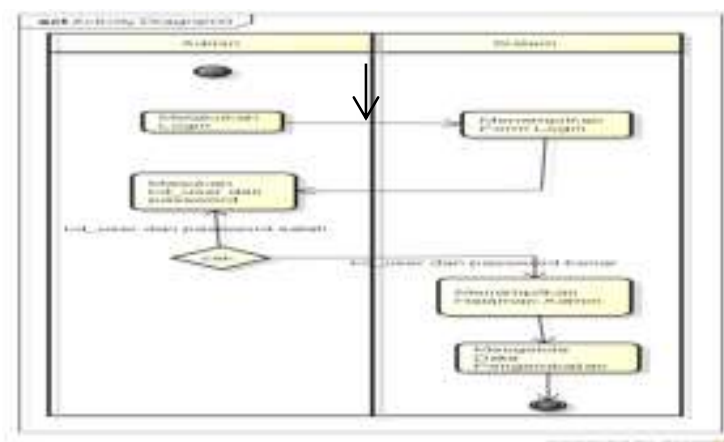

Gambar 11. Activity Diagram Admin Mengelola Data Pengembalian

Activity Diagram Admin Mengelola Data Laporan

Berikut adalah activity diagram admin mengelola data laporan yang dimana admin setelah proses login dengan memasukan kode user dan password admin dapat mengelola data laporan.

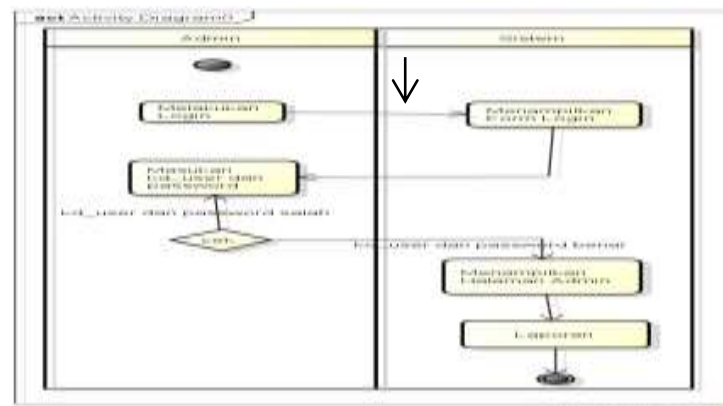

Gambar 12. Activity Diagram Admin Mengelola Data Laporan

206 | Perancangan Sistem Aplikasi Peminjaman dan Pengembalian Mobil di Rifaza Rental Mobil 


\section{Tampilan Layar(User Interface)}

Log In

Berikut dibawah ini form login untuk admin dan pemilik

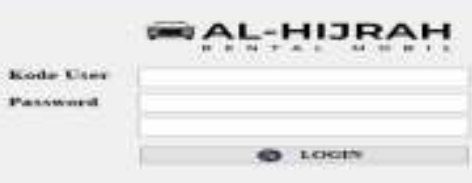

Gambar 13. Rancang Layar Login

Menu Utama Pemilik

Pemilik setelah login akan menampilkan menu pemilik seperti gambar dibawah ini.

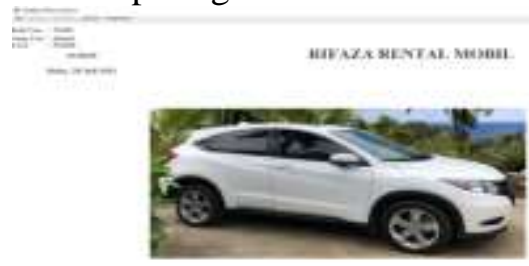

Gambar 14. Menu Utama Pemilik

Menu Utama Admin

Admin setelah login akan menampilkan menu admin seperti gambar dibawah ini.

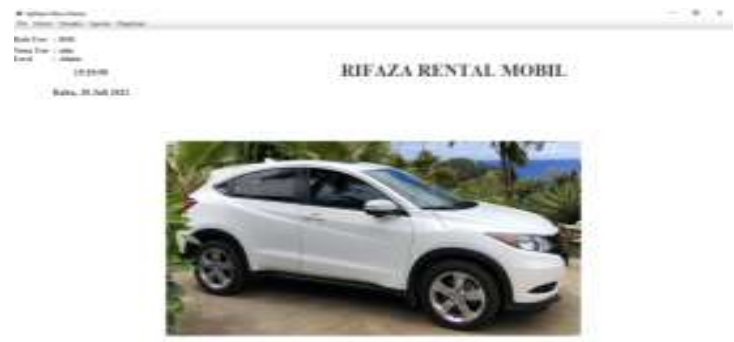

Gambar 15. Menu Utama Admin

Menu User

Di menu user ini admin dapat mengelola data user

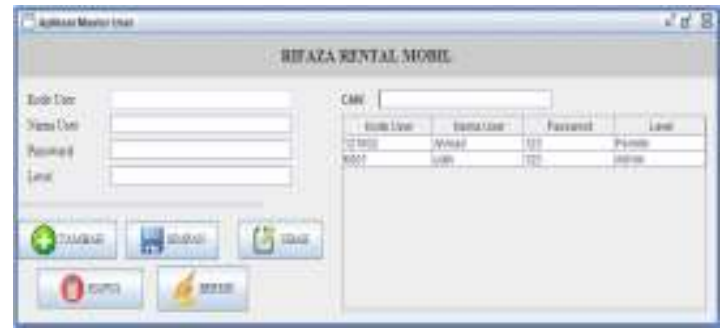

Gambar 16. Menu User

Menu Mobil

Di menu mobil ini admin dapat mengelola data mobil

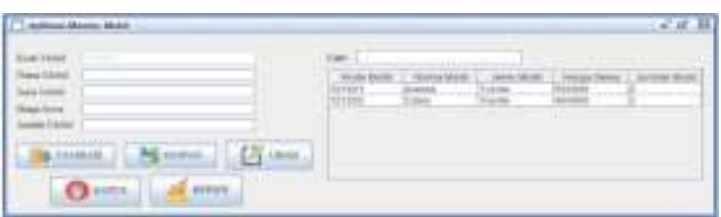

Gambar 17. Menu Mobil

Menu Pelanggan

Di menu pelanggan ini admin dapat mengelola data pelanggan

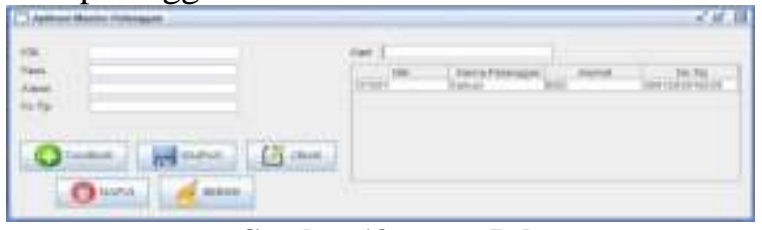

Gambar 18. Menu Pelanggan

Menu Peminjaman

Di mеnu peminjaman ini admin dapat mengelola data peminjaman

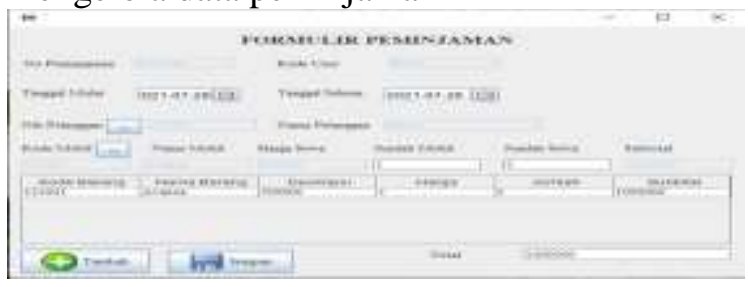

Gambar 19. Menu Peminjaman

Menu Pengembalian

Di menu pengembalian ini admin dapat mengelola data pengembalian

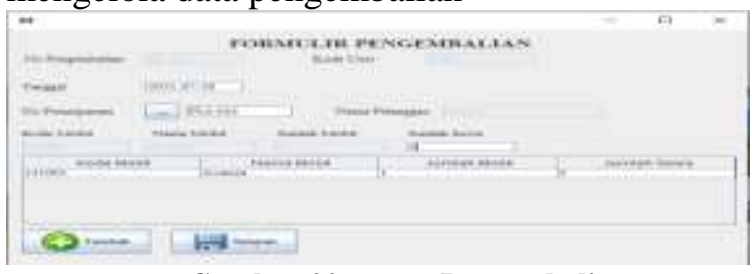

Gambar 20. Menu Pengembalian

Menu Laporan Pinjam

Di menu laporan pinjam ini admin dan pemilik dapat mengelola data laporan pinjam

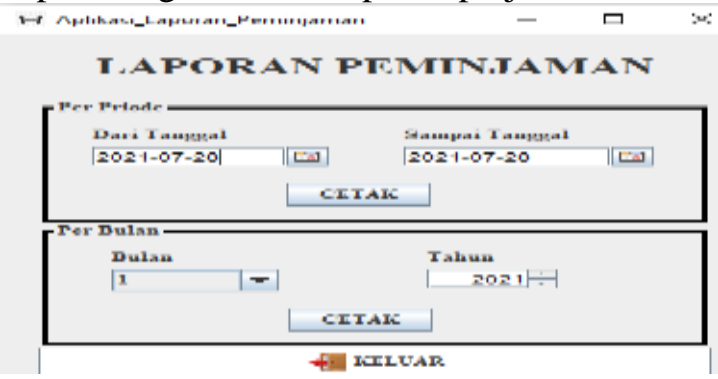

Gambar 21. Menu Laporan Pinjam

207 | Perancangan Sistem Aplikasi Peminjaman dan Pengembalian Mobil di Rifaza Rental Mobil 
Menu Laporan Pengembalian

Di menu laporan pinjam ini admin dan pemilik dapat mengelola data laporan pengembalian

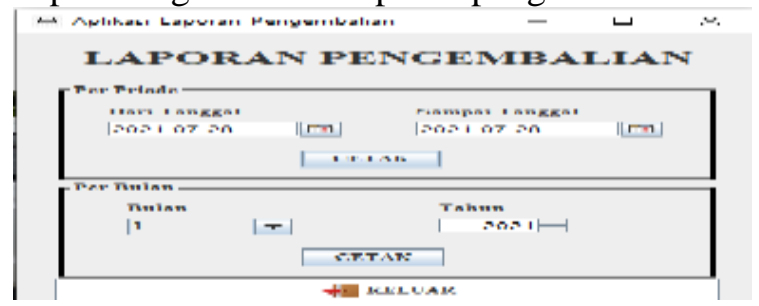

Gambar 22. Menu Laporan Pengembalian

\section{SIMPULAN DAN SARAN}

Berdasarkan kegiatan penelitian yang sudah dilakukan penuli selama perancangan hingga impementasi dan pengujian, maka dapat diambil kesimpulan dari hasil "Perancangan Sistem Aplikasi Peminjaman dan Pengembalian Mobil di Rifaza Rental sebagai berikut: Aplikasi ini hanya berlaku untuk satu kategori yaitu kasir sebagai admin untuk menembah atau mengurangi data peminjaman dan pengembalian mobil serta data mobil yang berada pada program aplikasi ini. Aplikasi ini tidak menangani input data secara online.

Adapun beberapa informasi rental mobil yang ditampilkan meliputi data peminjaman, data pengembalian, data mobil dan laporan harian yang akan diserahkan kepada pemilik. Penelitian ini diharapkan dapat membantu dalam mengembangkan pelayanan Rifaza Rental Mobil dalam bidang peminjaman dan pengembalian mobil.

Pada penelitian yang telah dilakukan ini, tentu saja banyak kekurangan dan kelemahannya. Oleh karena itu, terdapat beberapa hal yang perlu diperhatikan untuk membantu dalam pengembangan sistem kedepannya, antara lain : membantu untuk menyediakan menu pengisian secara online . User interface yang dibangun masih sangat sederhana, sehingga perlu dibuatkan rancangan yang lebih menarik. Misalnya dengan menambahkan animasi pada aplikasi. Sistem aplikasi bisa digunakan untuk admin dan pemilik sehingga input data lebih cepat dan pemilik hanya mengecek data peminjaman, data pengembalian, mengcek data mobil, data pelanggan, data user dan laporan.

\section{UCAPAN TERIMAKASIH}

Pada kesempatan yang baik ini, izinkanlah penulis menyampaikan rasa hormat dan ucapan terima kasih kepada semua pihak yang dengan tulus ikhlas telah memberikan bantuan dan dorongan kepada penulis dalam menyelesaikan penelitian ini, terutama kepada pemilik dan para karyawan di Rifaza Rental Mobil yang telah bersedia meluangkan waktunya dan menerima peneliti dengan baik.

\section{DAFTAR PUSTAKA}

Anomi. (2010). Perancangan Sistem Informasi Penyewaan Mobil Berbasis Web. Pelayanan Kesehatan, 2(2), 1.

Hakim, S. (2012). Mastering Java. Elex Media Komputindo.

Kurniawan, B., \& Herryanto, D. (2017). Perancangan Dan Implementasi Data Center Menggunakan File Transfer Protocol (Ftp). Perancangan Dan Implementasi Data Center Menggunakan File Transfer Protocol (Ftp), 2(2), 91-97.

Kusrini. (2011). Konsep dan Aplikasi Sistem Pendukung Keputusan. Andi.

Ladjamudin. (2005). Analisis dan Desain Sistem Informasi. GrahaIlmu.

Mulyadi. (2012). Sistem Informasi Akuntansi. Salemba Empat.

O'Brien. (2013). Management Information Systems. McGraw-Hill/Irwin.

Raymond Mcleod. (2012). Management Information Systems. Pearson Education.

Rizky. (2011). Konsep Dasar Rekayasa Perangkat Lunak. Prestasi Pustaka.

Sutabri, T. (2016). Sistem Informasi Manajemen (Edisi Revisi) (Revisi-1). Andi.

Wira, D., Putra, T., \& Andriani, R. (2019). Unified Modelling Language ( UML) dalam Perancangan Sistem Informasi Permohonan Pembayaran Restitusi SPPD. 7(1). 